\title{
BRUSH FIBER COMPLAINTS ON THE USE OF SITTING AND STANDING WORK
}

\author{
Anizar $^{1^{*}}$, Muhammad Zainul Bahri Torong ${ }^{2}$, Idhar Yahya ${ }^{2}$ \\ ${ }^{1}$ Department of Industrial Engineering, Faculty of Engineering, Universitas Sumatera Utara, Padang Bulan, Medan \\ 20155, Indonesia \\ Email : anizar usu@usu.ac.id \\ ${ }^{2}$ Department of Accounting, Faculty of Economic and Bussiness, Universitas Sumatera Utara, Padang Bulan, Medan \\ 20155, Indonesia \\ Email : zainulbahritorong1960@gmail.com , Email : $\underline{\text { idhar@usu.ac.id }}$
}

\begin{abstract}
Fiber brush production is entirely conducted manually by workers with the help of a very simple tool. Workers complain of experiencing pain in some parts of the body when working using sitting and standing postures. This study will evaluate the causes of pain complaints in workers who engage in fiber-binding and fiber-cutting activities. Pain complaints data are obtained from the Standard Nordic Questionnaire (SNQ) and work posture is assessed using the RULA and REBA methods. The assessment result shows that work method with unbalanced limb loadings induces pain complaints on workers. The choice between standing and sitting work posture is based on workload received by workers. Therefore, it is proposed to provide ergonomic work facilities in order to minimize the loading received by workers.
\end{abstract}

Keywords : fiber brush, pain complaints, ergonomic work facilities, work posture.

\section{INTRODUCTION}

Fiber brush making is a type of small business that small people work in and depends on to live, which makes brush fiber production plays a very important role in national economic development. Small businesses also absorb a massive number of workers nationally; they indirectly act as the motor of economic activity growth. However, workers are burdened with manual work that incorporates very limited working facilities. It causes workers to experience discomfort, fatigue and pain complaints pain in some parts of the body. Non-ergonomic work posture can causes complaints, ranging from mere discomfort to serious pain [1-2]. Work-related upper limb and neck musculoskeletal disorders (MSDs) are the most common complaints experienced by workers. Improving work facilities design can reduce the risks faced by workers [3]. Pain complaints may also be influenced by the use of non-ergonomic work facilities [4]. Changes in work methods and training to deal with musculoskeletal complaints will reduce work discomforts experienced by workers [5-7]. Ergonomic principle implementation will also reduce musculoskeletal disorders in workers [8].

Some of the production activities are cutting and binding the fiber, performed in a standing or sitting posture. Workers complains of experiencing pain for both activities, ranging from mild, moderate, to severe. None of the worker complain of experiencing severe pain for fiber-binding activity.

\section{METHOD OF ACTIVITY}

Pain complaints identification of workers in the fiber-binding and fiber-cutting activities is obtained by administering questionnaires: Standard Nordic Questionnaire (SNQ), which consists of 28 questions to 
Anizar. et al. Brush Fiber Complaints On The Use Of Sitting And Work.

obtain information regarding body pain complaints. The complaint criteria are as follows, 0 for no pain, 1 for mild pain, 2 for moderate pain, and 3 for severe pain.

Rapid Upper Limb Assesment (RULA) worksheet method is used to assess work posture score on fiber-binding activity, due to workers using the upper body more dominantly than lower body. Assesment is conducted on two groups: group A consisting of upper arms, forearms, and wrists; group B consisting of a neck, back, and feet. Rapid Entire Body Assesment (REBA) is used to assess work posture score on fiber-cutting activity. Assesment is conducted on two groups: group A consisting of trunk, neck, and legs; group B consisting of upper arms, forearms, and wrists.

The procedure of collecting data of workers for both activities is measuring the pulse of workers using a stopwatch. Before work starts, the measured pulse is recorded as Arterial Resting Pulse (ARP); after work finishes, the measured pulse is recorded as Arterial Working Pulse (AWP). The heart pulse is then measured again 3 times, with 30 seconds interval each, recorded as Pulse-1 (P1), Pulse-2 (P2), and Pulse-3 (P3) respectively.

Workers' physiological data is processed using direct and indirect assessment. Direct assessment is used to determine workload categories based on energy expenditure using the following equation,

$\mathrm{E}=1,80411-0,0229038 \mathrm{X}+4,71711 \cdot 10^{-4} \mathrm{X}^{2}$

where $\mathrm{E}$ is energy expenditure $(\mathrm{kcal} / \mathrm{min}) ; \mathrm{X}$ is heart rate (pulse/minute)

Energy expenditure of $100-200 \mathrm{kcal} / \mathrm{hour}$ is categorized as light workload, energy expenditure greater than $200-350 \mathrm{kcal} / \mathrm{hour}$ is categorized as medium workload, and energy expenditure greater than $350-500 \mathrm{kcal} / \mathrm{hour}$ is categorized as heavy workload.

Indirect assessment is used to determine workload categories based on heart pulse using the following equation,

\%CVL $=\frac{100 x \text { (ArterialWorkingFulse-ArterialRestingfulse) }}{\text { MaximumAnteriaIPulse-ArteriaIRestingPulse }}$

The maximum heart pulse is 220 -age for men and 200-age for women. The classifications are as follows: no fatigue for $\% \mathrm{CVL}$ of $0-29 \%$, needs improvement for \%CVL of 30\%-59\%, working is only allowed for a limited time for $\%$ CVL of $60 \%-79 \%$, immediate improvement is needed for \%CVL of $80 \%-99 \%$, and no work is allowed if \%CVL is larger than.

\section{RESULT AND DISCUSSIONS}

3.1. Complaints Pain In Worker's Body Among workers performing a fiber-binding activity, $35.71 \%$ of them complain of experiencing mild pain, $42.86 \%$ experiencing moderate pain, and none experiencing severe pain. $21.43 \%$ body parts that do not experience any pain are left and right thigh, left and right ankle, left and right foot. The body parts experiencing mild pain are the upper neck, left shoulder, left upper arm, left and right elbow, left forearm, left and right hand, left and right knee. The body parts experiencing moderate pain are the lower neck, right shoulder, back, right forearm, waist, hips, buttocks, right forearm, left and right wrist, left and right calf. Meanwhile, fiber-cutting activity causes $17.86 \%$ workers experiencing mild pain, $21.43 \%$ workers experiencing moderate pain, and $28.57 \%$ workers experiencing severe pain. Severe pain is experienced on the right shoulder, right upper arm, right elbow, right forearm, right wrist, right hand, right thigh, and right knee. It is shown in Figure 1. 




Figure 1. Workers complaints in brush fiber making process

Workers complain of pain in some body parts that can only be felt the night after work and will be normal again the day after. Workers performing fiber-binding activity have more pain complaints in comparison with those doing fiber-cutting activity, although none of the fiber-binding workers experiencing severe pain. Workers who bind fibers work in sitting work posture on a small bench for so long that makes some body parts to be bent in a long time. This activity has zero workloads. Workers performing fiber-cutting experience fewer pain complaints, yet these complaints range from mild to severe pain. These workers cut the fibrous bonding chain neatly using a manually operated cutting tool, which burdens the body. Tools improvement is expected to reduce pain complaints in some body parts.

\subsection{Work Posture Assessment}

There are have 4 elements of fiber-binding activity, i.e. taking bondings of small fibers from the gunny sack, throwing one end of the bonding to the floor, combining bondings of the small fibers 3-knots bondings, binding 3knots bondings into 1 big knots. The work posture is assessed using Rapid Upper Limb Assessment (RULA) method and the assessment is divided into group A and group B. Figure 2 shows a workers body's angle on each element of the activity.

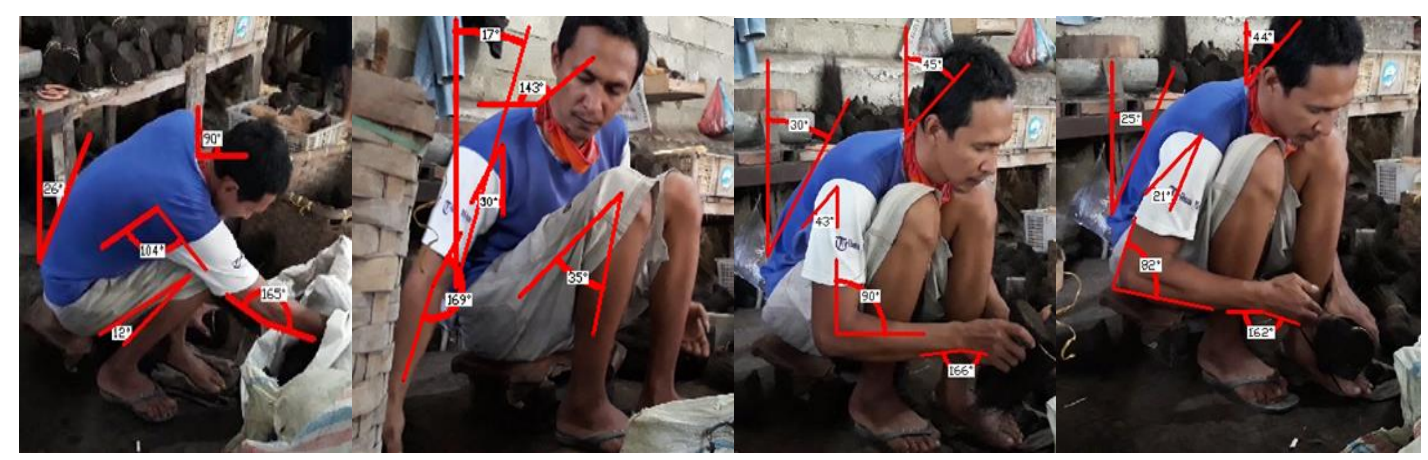

Figure 2. Fiber-binding elements of activity 
All element of activity is performed in sitting posture on a small bench, forming a slightly different angle on each activity. Taking bondings of small fiber from the gunny sack leave the worker's body to make an angle of $104^{\circ}$ at the upper arm, $165^{\circ}$ at the lower arm, $90^{\circ}$ at the neck, and $26^{\circ}$ at the trunk. The throwing one end of the bonding to the floor element of activity leaves the worker's body to make angle of $30^{\circ}$ at the upper arm; $169^{\circ}$ at the lower arm; $0^{\circ}-150^{\circ}$ at the wrist, wrist twisted in the midline; $143^{\circ}$ at the neck; and $17^{\circ}$ at the trunk. The combining bondings of the small fibers 3-knots bondings element of activity leaves the worker's body to make an angle of $43^{\circ}$ at the upper arm; $90^{\circ}$ at the lower arm; more than $15^{\circ}$ at the wrist, twisted with rotation; $45^{\circ}$ at the neck; and $30^{\circ}$ at the trunk. The element of activity of binding 3-knots bondings into 1 big knots leaves the worker's body to form angle of $21^{\circ}$ at the upper arm; $82^{\circ}$ at the lower arm; more than $15^{\circ}$ at the wrist, twisted at the final rotation; $44^{\circ}$ at the neck; and $25^{\circ}$ at the trunk. Based on the angle formed, it can be inferred that the element of activity of taking bondings of small fibers from the gunny sack and throwing one end of the bonding to the floor are of high risk level that requires immediate improvement of work posture, whereas the element of activity of combining bondings of the small fibers 3-knots bondings and binding 3-knots bondings into 1 big knots are of medium risk level that requires improvement of work posture in the near future. Assesment recapitulation of work posture for a fiber-binding element of activity is shown in Table 1.

Table 1. Recapitulation of work posture for fiber-binding elements of activity.

\begin{tabular}{lccl}
\hline \multicolumn{1}{c}{ Element of activity } & RULA Score & Risk Level & \multicolumn{1}{c}{ Action } \\
\hline $\begin{array}{l}\text { Taking bondings of small } \\
\text { fibers from the gunny sack }\end{array}$ & 7 & High & $\begin{array}{l}\text { Requires immediate } \\
\text { improvement }\end{array}$ \\
$\begin{array}{l}\text { Throwing one end of the } \\
\text { bonding to the floor }\end{array}$ & 7 & High & $\begin{array}{l}\text { Requires immediate } \\
\text { improvement }\end{array}$ \\
$\begin{array}{l}\text { Combining bondings of the } \\
\text { small fibers 3-knots bondings }\end{array}$ & 5 & Medium & $\begin{array}{l}\text { Requires improvement in } \\
\text { the near future } \\
\text { Binding 3-knots bondings } \\
\text { into 1 big knots }\end{array}$ \\
\hline
\end{tabular}

The elements of activity of taking bondings of small fibers from the gunny sack, throwing one end of the bonding to the floor obtained RULA score of 7, meaning that they require an immediate improvement. Improvement can be done by giving work facilities, such as ergonomic working table and chair that meet worker's anthropometry. Other 2 elements of activity obtained RULA score of 5 , meaning that they require improvement as well, although not an immediate improvement.
Workers doing fiber-cutting activity have three elements of activity, i.e. laying the fiber knots onto the cutting tool, cutting the fiber knots, and removing the cut fiber knots from cutting tools. The workers' body posture are assessed using Rapid Entire Body Assessment (REBA) method, divided into work posture of group A and group B. The worker's body angle on each element of the activity is shown in Figure 3. 

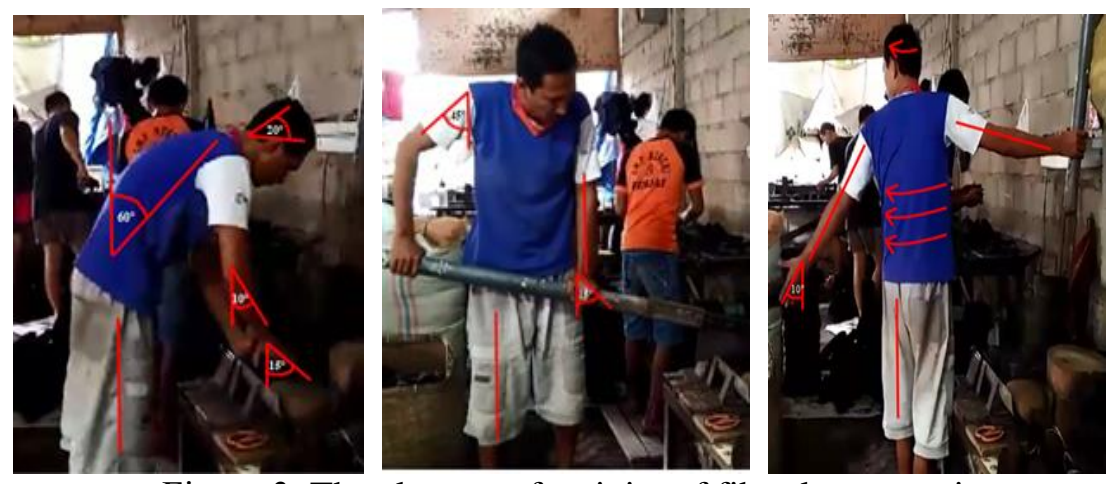

Figure 3. The element of activity of fiber-knots-cutting

Fiber-cutting activity is performed in standing work posture with a small workload, yet the body angle formed on the three elements of activity do not differ much. The activity is performed with the position of the head tilt downward forming angle of $0^{\circ}-20^{\circ}$, feet straight, wrist bend $0^{\circ}-15^{\circ}$, forearms swing with an angle of $0^{\circ}-60^{\circ}$, and the handgrip is firm enough, although still not ideal. The trunk on the activity of laying the fiber knots is in backward bent position with the angle of $0^{\circ}$ $20^{\circ}$, and straight for the activity of removing the fiber knots from the cutting tool. Upper arm position for the activity of laying the fiber knots onto and removing the fiber knots from the cutting tool makes an angle of $20^{\circ}-45^{\circ}$, while it forms

$0^{\circ}-20^{\circ}$ for the cutting phase. Based on this information, it can be inferred that the activities of moving the fiber into and out of the cutting tool are classified as a medium risk with a level action of 2: improvement needed. On the other hand, the act of cutting the fiber knots actually reaches a score of 3 , meaning that immediate improvement is needed. Score recapitulation of work posture assessment for fiber-cutting activity is shown in Table 2 .

Table 2. Score recapitulation of work posture assessment for fiber-cutting activity.

\begin{tabular}{lccc}
\hline \multicolumn{1}{c}{ Element of activity } & REBA Score & Risk Level & Action \\
\hline $\begin{array}{l}\text { Laying the fiber knots onto the } \\
\text { cutting tool }\end{array}$ & 4 & Moderate & Need improvement \\
$\begin{array}{l}\text { Laying the fiber knots onto the } \\
\text { cutting the fiber knots }\end{array}$ & 7 & Moderate & Need improvement \\
$\begin{array}{l}\text { Removing the cut fiber knots } \\
\text { from cutting tools }\end{array}$ & 4 & Moderate & Need improvement \\
\hline
\end{tabular}


The element activity of laying the fiber knots onto the cutting tool and removing the cut fiber knots from cutting tools obtain REBA score of 4 , while cutting the fiber knots obtains REBA score of 7 , meaning that they need improvement, although not that urgent. Improvement can be done by giving the more ergonomic working tool to minimize complaints of pain during working.

\subsection{Energy Expenditure}

Workers performing fiber-binding consume approximately $275.95 \mathrm{kcal} / \mathrm{h}$, classified as a medium workload category, and the percentage of a cardiovascular load is $23.96 \%$, classified as experiencing no fatigue category. Meanwhile, fiber-cutting consumes approximately $345.6 \mathrm{kcal} / \mathrm{h}$, classified as a medium workload, and the percentage yoof cardiovascular load is $30.77 \%$, classified as immediate improvement is needed.

\section{CONCLUSION}

This article aims to obtain the data regarding pain complaints of workers who work using standing and sitting work posture. Workers performing fiber-binding activity experience more pain complaints on their body parts compared to workers performing a fibercutting activity. However, the pain complaints of workers performing the latter activity are more severe. It can be inferred that the pain complaints experienced by workers are not only influenced by working posture, but also by the workload received. Improvement of work facilities can reduce the pain complaints experienced by the workers.

\section{ACKNOWLEDGMENTS}

The authors gratefully acknowledge that the present research is supported by Ministry of Research and Technology and Higher Education Republic of Indonesia. The support is under the research grant Non -PNBP USU of Year 2018 Contract Number 172/UN5.2.3.2.1/PPM/2018

\section{BIBLIOGRAPHY}

[1] Rahman CML 2014 International Journal of Engineering and Applied Sciences 5(3)

[2] Rahman CML, Uddin SM, Karim MA, Ahmed M 2015 International Journal of Engineering and Applied Sciences 10(6) 2542-2550

[3] Hoe VC, Urquhart DM, Kelsall HL, Sim MR 2012 J. Occup Environ Med 69(3) 198-204

[4] Meira Mainenti MR, Felicio LR, Rodrigues EC, Ribeiro da Silva DT, Santos PV 2014 J. Phys Ther Sci. 26(4): 567-573

[5] Lowe BD, Shaw PB, Wilson SR, Whitaker JR, Witherspoon GJ, Hudock SD, Barrero M, Ray TK, Wulzelbacher SJ 2017 J. Occup Environ Med 59(6) 563-570

[6] Anizar, Matondang AR, Sibarani JA 2018 IOP Conf. Ser.: Mater. Sci. Eng. 309012004

[7] Heneghan NR, Baker G, Thomas K, Falla D, Rushton A 2018 BMJ Open 8(5)

[8] Mali SC, Vyavahare RT 2015 International Journal of Current Engineering and Technology 5(3) $1820-1826$ 